\title{
Exploring the relationship between stress and acne: a medical student's perspective
}

This article was published in the following Dove Press journal:

Clinical, Cosmetic and Investigational Dermatology

\author{
Aryan Maleki \\ Noorulain Khalid \\ Faculty of Medicine, Barts and The \\ London School of Medicine and \\ Dentistry, London, UK
}

Correspondence: Aryan Maleki Barts and The London School of Medicine and Dentistry, 4 Newark Street, Whitechapel, London, EI 2AT, UK Email a.maleki@smdI5.qmul.ac.uk

\section{Dear editor}

We read with great interest the paper by Zari and Alrahmani ${ }^{1}$ investigating the relationship between stress and acne among female medical students. These findings are relevant as around $20 \%$ of young people are affected by moderate-to-severe acne, and indeed acne severity is associated with increased risks of anxiety, depression, and suicidal ideation. ${ }^{2}$ The authors identified that "stress severity strongly correlated with an increase in acne severity," and suggested that stress likely has an important role in the pathogenesis of acne. ${ }^{1}$ However, the paper could have been taken further to better establish the true extent of this relationship, and ultimately whether certain patients will benefit from clinical interventions based on their perceived stress scale.

One way a stronger causal relationship may be achieved is by evaluating whether stress-reduction techniques can significantly reduce acne severity. As medical students in our clinical years, we ourselves are subject to high levels of stress, and have experienced first-hand the effectiveness of stress-reduction techniques in our curriculum via student selected components (SSCs) at Barts and The London School of Medicine. ${ }^{3}$ SSCs, such as Mindfulness and Clinical Hypnosis, focus on developing a greater understanding and awareness of when we are stressed and recommend a variety of stress management tools. These relaxation techniques can reduce anxiety and improve overall mental health, which is also strongly linked to higher academic performance. ${ }^{4}$ Investigating reductions in student stress and acne in the months following these SSCs could provide strong evidence for a causal relationship and further offer practical solutions to help acne sufferers. It would also aid in distinguishing whether the stress leading to acne originates from extrinsic factors or whether it is due to an individual's "intrinsic" predisposition to produce stress responses.

Furthermore, the design of this paper was a cross-sectional study, and so the use of questionnaires to establish cause-and-effect relationships may be hindered by recall bias. Acne is known to negatively affect quality of life and mood, so it is possible acne can lead to stress and not vice versa. ${ }^{5}$ To help address this issue, we recommend measuring student stress and acne levels at different times during the medical course and comparing values relative to each individual. The paper by Zari and Alrahmani ${ }^{1}$ 
does not necessarily recognize this limitation, and so perhaps in addition to the research conducted, this would be useful.

We believe the effects of stress-reducing techniques on acne severity merit further investigation. Evaluating the influence of lifestyle factors, such as exercise and sleep, on stress and acne would also be interesting due to the lack of research in this field. Lastly, conducting studies on both sexes rather than female students alone should be considered for future research.

\section{Disclosure}

The authors report no conflicts of interest in this communication.

\section{References}

1. Zari S, Alrahmani D. The association between stress and acne among female medical students in Jeddah, Saudi Arabia. Clin Cosmet Investig Dermatol. 2017;10:503-506.

2. Bhate K, Williams HC. Epidemiology of acne vulgaris. Br J Dermatol. 2013;168(3):474-485.

3. Barts and The London School of Medicine and Dentistry. Curriculum map for Barts and The London School of Medicine and Dentistry's MBBS programme. Whitechapel, London: Barts and The London School of Medicine and Dentistry; 2010. Available from: https://compas.smd. qmul.ac.uk/. Accessed December 21, 2017.

4. Keong PP, Sern LC, Lee MF, Ibrahim C. The relationship between mental health and academic achievement among university students - a literature review. Second International Conference on Global Trends in Academic Research. 2015;2:755-764.

5. Yazici K, Baz K, Yazici AE, et al. Disease-specific quality of life is associated with anxiety and depression in patients with acne. J Eur Acad Dermatol Venereol. 2004;18(4):435-439.

Dove Medical Press encourages responsible, free and frank academic debate. The content of the Clinical, Cosmetic and Investigational Dermatology 'letters to the editor' section does not necessarily represent the views of Dove Medical Press, its officers, agents, employees, related entities or the Clinical, Cosmetic and Investigational Dermatology editors. While all reasonable steps have been taken to confirm the content of each letter, Dove Medical Press accepts no liability in respect of the content of any letter, nor is it responsible for the content and accuracy of any letter to the editor.

Clinical, Cosmetic and Investigational Dermatology

\section{Publish your work in this journal}

Clinical, Cosmetic and Investigational Dermatology is an international, peer-reviewed, open access, online journal that focuses on the latest clinical and experimental research in all aspects of skin disease and cosmetic interventions. This journal is included on PubMed. The manuscript management system is completely online
Dovepress

and includes a very quick and fair peer-review system, which is all easy to use. Visit http://www.dovepress.com/testimonials.php to read real quotes from published authors 